\title{
Fear of crime and psychological and physical abuse associated with ill health in a Swedish population aged 65-84 years
}

Niclas Olofsson, Kent Lindqvist and I Danielsson

\section{Linköping University Post Print}

N.B.: When citing this work, cite the original article.

Original Publication:

Niclas Olofsson, Kent Lindqvist and I Danielsson, Fear of crime and psychological and physical abuse associated with ill health in a Swedish population aged 65-84 years, 2012, Public Health, (126), 4, 358-364.

http://dx.doi.org/10.1016/j.puhe.2012.01.015

Copyright: WB Saunders http://www.elsevier.com/

Postprint available at: Linköping University Electronic Press

http://urn.kb.se/resolve?urn=urn:nbn:se:liu:diva-76948 


\section{Fear of crime and psychological and physical abuse associated with ill health in a Swedish population aged $65-84$}

Niclas Olofsson, MSc, Department of Medical and Health Sciences, Division of Social

Medicine and Public Health Science, Linköping University, Linköping, Sweden

Kent Lindqvist, MPH, PhD, Department of Medical and Health Sciences, Division of Social Medicine and Public Health Science, Linköping University, Linköping, Sweden Ingela Danielsson, MD, PhD, Department of Research and Development, Västernorrland County Council, Sundsvall and Department of Clinical Science, Obstetrics and Gynaecology, Umeå University, Umeå, Sweden

Corresponding author: Niclas Olofsson, County Council of Västernorrland, SE-871 85

Härnösand, Sweden

Telephone: +46 61180078, Fax: +46 61180026

E-mail: niclas.olofsson@1vn.se 


\section{Abstract}

Objectives

The objective of the paper was to assess the association between experiencing fear of crime and/or psychological and/or physical abuse in relation to self-reported physical and psychological health, using a large representative sample of elderly women and men in Sweden.

Study design

Cross-sectional national survey

Methods

Data were taken from a nationwide representative public health survey (2006). Men and women between the ages of 65 and 84 were selected for the analyses in the study, which comprised 4,386 men and 4,974 women. The response rate for this age group was $59 \%$ for men and $70 \%$ for women.

\section{Results}

Psychological and physical abuse against elderly women and men produced raised odd ratios for negative health outcomes, independently of socio-economic status. Strong correlation between psychological abuse and negative health outcomes was found in both men and women, while physical abuse showed less significantly raised odds ratios, especially among women. The men in particular had high odds ratios for suicidal thoughts and even for attempted suicide in connection with physical and psychological abuse and fear of crime.

\section{Conclusions}

The study provides representative results addressing an extensive negative health outcome panorama caused by fear of crime and exposure to abuse. 


\section{Introduction}

Abuse of the elderly is a recent form of violence to come to public attention, but it remains a largely hidden problem. Abuse of this kind is an important public health and human rights issue. A WHO (World Health Organization) report on violence and health highlights the existence of a wide range of activities and manifestations that the elderly may be exposed to in different social and cultural groups throughout the world ${ }^{1}$. As one source puts it, 'The incidents differ - the burning of a so called witch in Mozambique, the punching of a nursing home resident in the USA, the violent robbery of a fruit-seller in Brazil - but they share a common factor: all are examples of abuse against elderly people... ${ }^{2}$. Elder abuse is often defined as any action, or any lack of appropriate action, that causes harm, intentionally or unintentionally, to an elderly person ${ }^{3}$. The main types of abuse that have been identified are physical, psychological or emotional, sexual and financial abuse, and negligence ${ }^{1,4,5}$. There is a wide range (3-27\%) of prevalence of elderly abuse reported in general population studies from different countries, reflecting true variation in abuse rates across cultures as well as possibly differences in measurement methods ${ }^{6}$.

Several studies have reported that severe abuse among women and men declines with age $e^{3,7-}$ ${ }^{10,30}$. Elderly have a reduced risk of being personally abused, yet they still have a high degree of fear of crime ${ }^{11}$. Crucially for elderly, fear of crime can deter from participating in everyday activities and potentially decrease personal choices and mobility ${ }^{12}$.

Research has confirmed a relation between elderly abuse and ill health in studies concerning, for instance, domestic violence ${ }^{8,13}$ limited populations such as primary care settings ${ }^{14}$ and independent living settings ${ }^{15,16}$. Physical abuse may have both physical and psychological consequences $^{16-19}$. Elderly persons who are victims of psychological abuse are more likely to experience poor physical health and emotional and/or mental impairment than the non-abused population $^{20}$. Not only abuse but a fear of crime is also shown to be associated with poorer 
mental health, limitations in physical functioning and lower quality of life, even if this is less studied $^{21,22}$.

There are however very few large population-based studies that assess the link between elder fear of crime, elder abuse and ill health. The aim of the current study is to assess the association between experiencing a fear of crime and/or psychological and/or physical abuse in relation to self-reported physical and psychological health, using a large representative sample of elderly men and women in Sweden.

\section{Method}

Data from a nationwide public health survey conducted by the Swedish National Institute of Public Health in 2006 were analysed. A nationally representative sample of close to 60,000 women and men aged 16-84 had been asked to reply to a questionnaire, called Equal Health?, sent to them by mail. In this present analysis men and women between the ages of 65-84 were selected, which comprised 4,974 women and 4,386 men. The response rate for this age group was $70 \%$ for women and $59 \%$ for men.

The questionnaire contained 77 questions, 42 of which were about physical and mental health and use of the health care system, 30 pertained to socioeconomic factors, form of housing, and work environment, and five dealt with cigarette smoking and use of alcohol. Questions concerning abuse were included under the heading 'Security'. A question involving fear of crime was worded, 'Has it ever happened that you refrained from going outdoors alone because you were afraid of being assaulted, robbed or in any way molested during the past 12 months?'. The alternative responses to this question were (1) 'No', (2) 'Yes, sometimes' and (3) 'Yes, often'. To assess psychological abuse, the following two questions were used: 'Have you been verbally offended during the past 12 months?' (with response alternatives [1] 'No', 
[2] 'Yes, sometimes' and [3] 'several times') and 'Have you been exposed to any threats or threats of violence that made you scared during the past 12 months?' (with binary answer alternatives). Two questions regarding physical abuse were worded as follows: (1) 'Have you been exposed to physical violence during the last 12 months?' and (2) 'If so, where did it happen?'; (1) had binary answers while (2) offered several given alternatives. Self-rated health was assessed using the question, 'How do you rate your general state of health?'; the alternative answers were (1) 'very good', (2) 'good', (3) 'fair', (4) 'poor' and (5) 'very poor'. The responses were then further dichotomized, (1) and (2) as good and (3), (4) and (5) as poor. This question has high validity in relation to both psychological and physical health ${ }^{23,24}$. To assess mental health, the 12 questions from the General Health Questionnaire (GHQ 12) were included. The GHQ is one of the most thoroughly tested questionnaires regarding mental health and is used for screening current general psychological and psychiatric disorders ${ }^{25}$. Alcohol use was assessed using the Alcohol Use Disorders Identification Test (AUDIT), constructed by WHO in 1992 and widely used for adults. The first three questions (AUDIT C) regarding consumption were used, and different cut-off values for women and men were chosen to discriminate for hazardous drinking ${ }^{26}$. For smoking, one question was chosen, namely, 'Are you a daily smoker?'.

Questions that were relevant to the age group regarding health and socioeconomic factors were chosen for the analyses of this study. Most health variables had three response categories: 'No'; 'Yes, some problems'; and 'Yes, severe problems'. These were dichotomized into (1) No and Yes, some problems; and (2) Yes, severe problems. A question about ethnicity was divided into two categories: (1) born in Sweden and/or other Nordic country (Norway, Denmark, Finland, Iceland) or (2) born in some other country. Civil status was trichotomized into (1) married or cohabiting or (2) single or (3) widowed. Regarding education, the answers were trichotomized into: (1) all levels of education less than a total of 
11 years, (2) education of 12 to 14 years and (3) 15 years of education or more. Working history was dichotomized into (1) manual and (2) non-manual. Economic margin was evaluated by use of the question, 'If you suddenly needed 15,000 kronor (approximately 1,500 euro), could you manage to get it in one week?'. A pharmaceutical index was constructed using the added declared pharmaceuticals, as was a use of health care index, using added reported visits to various health care facilities.

The statistical analyses were conducted using the SPSS program 17.0. Binary logistic regression was used to analyse possible associations between abuse and socioeconomic factors and different health outcomes. Multivariate logistic regression was used to analyse the association between abuse and health outcomes, controlling for socioeconomic factors and smoking. The significance level used was $<0.05$. Prevalence, with a $95 \%$ confidence interval, was used to describe and analyse differences in socioeconomic background (education, unemployment, financial situation and civil status), smoking, hazardous alcohol use and use of cannabis, for those exposed to abuse compared with those not exposed. Generally, when comparing two parameter estimates, the estimates are statistically significant different if the confidence intervals do not overlap ${ }^{43}$.

All participants were informed about the study in a cover letter enclosed with the questionnaire. Answering the questionnaire was judged to be consent to join the study. The Ethics Committee at the Swedish National Board of Health and Welfare approved the survey.

\section{Results}

The sample characteristics and prevalence of exposure to the different forms of abuse are reported for two age classes, to differentiate between younger elderly (65-74) and older elderly (75-84). To guarantee a sufficient sample foundation, only one age class, 65-84, was used for the logistic regression analyses. 
The socioeconomic characteristics of the population are given in Table 1. Irrespective of sex and age, the majority of the elderly population was born in Sweden, married or cohabiting, had a shorter form of education and lived in a home of their own. The women more frequently reported living in a single household (specifically being widowed) and having a lower educational base, more difficult economic situation and lower percentage of risk consumption of alcohol than the men.

A higher percentage of women than men also answered that they had refrained from going outdoors alone because they were afraid of being assaulted, robbed or in some way molested (fear of crime) (Table 2). Psychological abuse was more prevalent than physical abuse in both men and women, and both psychological and physical abuse decreased with age. No substantial difference between the sexes was found in this respect (Table 2). Figure 1 illustrates the overlapping of physical and psychological abuse and the perception of fear of crime. Fear of crime and psychological abuse overlap considerably in both women (51\%) and men $(48 \%)$. There is almost no overlapping between physical abuse and psychological abuse among the women (5.3\%), but the men report more concurrent forms of abuse (psychological and physical abuse in 39\%; physical and fear of crime in 15\%)(Figure 1).

More than twice as many women reported being exposed to physical abuse in their home compared to men, while almost all physical abuse in public places (restaurant, nightclub or the like) was directed against a man (Figure 2). About $50 \%$ of both men and women reported having been abused in other places, which was not further specified in the questionnaire. Adjusted odds ratios for different health outcomes and use of medical care are given for women and men in perceiving vs. not perceiving fear of crime and being vs. not being exposed to psychological and/or physical abuse (Table 3). All the odds ratios have been adjusted for age, civil status, working history and smoking. In general, a considerable amount of the odds ratios for both men and women who perceived a fear of crime or reported being 
Table 1. Sample characteristics stratified according to sex and age, percentage (95\% confidence interval)

\begin{tabular}{lrrrr}
\hline Characteristics & Women 65-74 & Men 65-74 & Women 75-84 & Men 75-84 \\
& $\mathrm{n}=2973$ & $\mathrm{n}=2686$ & $\mathrm{n}=2001$ & $\mathrm{n}=1700$ \\
\hline $\begin{array}{l}\text { Ethnicity } \\
\quad \text { Born in Nordic country }\end{array}$ & $87(86-88)$ & $86(85-87)$ & $89(88-90)$ & $91(90-92)$ \\
Civil status & & & \\
$\quad$ Married/cohabiting & $74(72-76)$ & $90(89-91)^{\#}$ & $47(45-49)$ & $74(72-76)^{\#}$ \\
$\quad$ Single & $8.1(7.1-9.1)^{\#}$ & $3.9(3.2-4.6)$ & $5.9(4.9-6.9)$ & $5.3(4.2-6.4)$ \\
$\quad$ Widowed & $13(12-14)^{\#}$ & $1.7(1.2-2.2)$ & $41(39-43)^{\#}$ & $11(10-12)$
\end{tabular}

\section{Education}

\begin{tabular}{lrrrr} 
Short & \multicolumn{1}{c}{$\begin{array}{r}\text { (79-80) } \\
\text { Intermediate }\end{array}$} & $67(65-69)$ & $81^{\#}(79-83)$ & $70(68-72)$ \\
Long & $10(9-11)$ & $25(23-27)^{\#}$ & $11(10-12)$ & $17(15-19)^{\#}$ \\
& $11(10-12)^{\#}$ & $8(7-9)$ & $8(7-9)$ & $13(11-15)^{\#}$
\end{tabular}

\section{Working history}

Manual

$46(44-48)$

$47(45-49)$

$54^{\#}(52-56)$

$45(43-47)$

\section{Accommodation}

\begin{tabular}{lrrrr}
\multicolumn{1}{l}{ Own house/ apartment } & $73(71-75)$ & $76(74-78)$ & $63(61-65)$ & $69(67-71)^{\#}$ \\
\multicolumn{1}{l}{ Rental apartment } & $24(22-26)$ & $20(18-22)$ & $32(30-34)^{\#}$ & $25(23-27)$ \\
$\quad$ Other & $3.0(2.4-3.6)$ & $4.0(3.3-4.7)$ & $5.0(4.0-6.0)$ & $6.0(4.9-7.1)$ \\
Insufficient economic margin & $18(17-19)^{\#}$ & $12(11-13)$ & $18(16-20)^{\#}$ & $10(9.0-11)$ \\
Daily smoking & $13(12-14)$ & $12(11-13)$ & $7(6.0-8.0)$ & $11(10-12)^{\#}$ \\
Risk consumption of alcohol & $3.0(2.4-3.6)$ & $7.0(6.0-8.0)^{\#}$ & $0.1(0-0.2)$ & $3.0(2.2-3.8)^{\#}$
\end{tabular}

\# = Statistically significant different percentage estimate between men and women in the same age category. 
Table 2. Self-reported prevalence of fear of crime and abuse in the population, stratified by sex and age, percentage (95\% confidence interval)

\begin{tabular}{lllll}
\hline Characteristics & Women 65-74 & Men 65-74 & Women 75-84 & Men 75-84 \\
& $\mathrm{n}=2973$ & $\mathrm{n}=2686$ & $\mathrm{n}=2001$ & $\mathrm{n}=1700$ \\
& $\%(\mathrm{c} . \mathrm{i})$. & $\%(\mathrm{c} . \mathrm{i})$. & $\%(\mathrm{c} . \mathrm{i})$ & $\%$ (c.i.) \\
\hline Fear of crime & $41(39-43)^{\#}$ & $12(11-13)$ & $44(42-46)^{\#}$ & $18(16-20)$ \\
Psychological abuse & $8.7(7.7-9.7)$ & $8.9(7.8-10)$ & $6.4(5.3-7.5)$ & $5.0(4.0-6.0)$ \\
Physical abuse & $1.0(0.6-1.4)$ & $3.0(2.4-3.6)^{\#}$ & $0.6(0.3-0.9)$ & $0.2(0-0.4)$ \\
\hline
\end{tabular}

\# = Statistically significant different percentage estimate between men and women in the same age category.

exposed to psychological abuse were significantly raised. Only blood pressure did not show any raised odds ratios, when comparing men and women who had or had not reported being exposed to psychological or physical abuse or experienced fear of crime. Regarding physical abuse, the odd ratios for negative health outcomes were more often significantly raised for the men than for the women. As expected, anxiety, sleeping problems, stress and psychological health (GHQ12) stand out as problem areas irrespective of sex and negative exposure. The odds for suicidal thoughts and attempted suicide were highly increased for men experiencing fear of crime or psychologically or physically abuse but only for psychological abuse among the women. 
Table 3. Adjusted odds ratios (OR) and confidence intervals ${ }^{1}$ for health outcomes adjusted for age, civil status, work history and smoking for women and men experiencing fear of crime and/or being psychologically or physically abused during the past 12 months, compared to non-abused (age 65-84).

\begin{tabular}{|c|c|c|c|c|c|c|}
\hline & \multicolumn{2}{|c|}{ Fear of crime } & \multicolumn{2}{|c|}{ Psychological abuse } & \multicolumn{2}{|c|}{ Physical abuse } \\
\hline & Women & Men & Women & Men & Women & Men \\
\hline Poor general & $1.1(1.0-1.1)$ & $1.6(1.1-2.4)$ & $3.8(2.7-5.3)$ & $2.2(1.4-3.4)$ & $1.2(0.5-2.6)$ & $2.2(1.2-4.1)$ \\
\hline \multicolumn{7}{|l|}{ health } \\
\hline Muscular/skeletal & $1.1(0.9-1.3)$ & $1.0(0.8-1.4)$ & $2.2(1.7-2.9)$ & $2.1(1.5-2.9)$ & $2.1(0.7-5.9)$ & $2.6(1.7-4.2)$ \\
\hline \multicolumn{7}{|l|}{ pain (index) } \\
\hline Headache & $1.3(1.1-1.6)$ & $1.7(1.3-2.4)$ & $1.5(1.1-2.0)$ & $2.1(1.4-3.0)$ & $1.5(0.9-2.4)$ & $1.8(1.1-3.2)$ \\
\hline Incontinence & $1.1(0.9-1.3)$ & $1.2(0.8-1.6)$ & $1.6(1.2-2.1)$ & $1.7(1.2-2.4)$ & $1.8(1.2-2.9)$ & $2.3(1.4-3.7)$ \\
\hline Stomach problem & $1.4(1.2-1.6)$ & $1.5(1.1-1.9)$ & $2.0(1.6-2.6)$ & $1.3(1.0-1.9)$ & $1.5(0.9-2.4)$ & $1.1(0.1-1.7)$ \\
\hline Overweight & $1.2(1.1-1.4)$ & $1.5(1.2-2.0)$ & $1.4(1.0-1.8)$ & $1.4(1.0-1.9)$ & $1.3(0.8-2.1)$ & $1.7(1.1-2.7)$ \\
\hline Diabetes & $1.0(0.8-1.2)$ & $1.2(0.9-1.7)$ & $1.4(0.9-2.0)$ & $1.2(0.8-1.9)$ & $1.5(0.8-3.1)$ & $1.7(1.0-2.9)$ \\
\hline Allergy & $1.2(1.0-1.5)$ & $1.8(1.3-2.6)$ & $1.8(1.4-2.5)$ & $2.2(1.5-3.3)$ & $1.8(1.1-3.1)$ & $1.3(0.7-2.4)$ \\
\hline Blood pressure & $1.1(0.9-1.3)$ & $1.3(0.9-1.7)$ & $0.9(0.7-1.2)$ & $1.2(0.9-1.7)$ & $1.2(0.7-2.0)$ & $1.1(0.7-1.7)$ \\
\hline Anxiety & $1.8(1.2-2.9)$ & $1.9(0.9-4.0)$ & $6.3(3.7-11)$ & $10(5.3-19)$ & $7.4(3.6-15)$ & $7.1(3.0-16)$ \\
\hline Sleeping problem & $1.5(1.2-2.0)$ & $2.5(1.6-4.0)$ & $3.0(2.0-4.3)$ & $3.5(2.1-5.9)$ & $2.3(1.4-4.5)$ & $5.1(2.8-9.3)$ \\
\hline Stress & $1.6(1.2-2.3)$ & $3.3(2.0-5.3)$ & $6.3(4.2-9.3)$ & $5.7(3.5-9.5)$ & $3.8(1.9-7.6)$ & $5.9(3.1-11)$ \\
\hline Ghq12 & $1.5(1.2-1.9)$ & $2.2(1.6-3.1)$ & $5.9(4.4-7.9)$ & $3.9(2.7-5.7)$ & $4.0(2.4-6.7)$ & $3.2(1.9-5.5)$ \\
\hline Suicidal thoughts & $1.1(0.8-1.5)$ & $3.7(2.3-5.7)$ & $3.5(2.3-5.2)$ & $7.3(4.6-11)$ & $1.9(0.9-4.3)$ & $4.7(2.4-9.0)$ \\
\hline Attempted suicide & $1.4(0.8-2.4)$ & $4.0(1.8-8.7)$ & $1.1(0.4-2.8)$ & $5.3(2.3-12)$ & $1.4(0.3-6.0)$ & $5.4(1.8-16)$ \\
\hline Pharmaceutical & $1.1(1.0-1.4)$ & $2.0(1.4-2.7)$ & $2.0(1.5-2.7)$ & $2.1(1.4-3.0)$ & $2.1(1.2-3.4)$ & $3.3(2.0-5.4)$ \\
\hline index & & & & & & \\
\hline Use of & $1.3(1.0-1.5)$ & $1.6(1.2-2.1)$ & $2.6(1.9-3.5)$ & $1.4(0.9-2.1)$ & $1.8(1.0-3.1)$ & $1.2(0.7-2.2)$ \\
\hline healthcare inde & & & & & & \\
\hline
\end{tabular}

1. Statistically significant OR are bolded 


\section{Discussion}

In this study we have shown that psychological and physical abuse against elderly women and men produced raised odd ratios for negative health outcomes, independently of socioeconomic status. Above all there was a strong correlation between psychological abuse and negative health outcomes in both men and women, while physical abuse showed less significantly raised odds ratios among especially the women. Noteworthy as well is that men had high odds ratios for suicidal thoughts and even for attempted suicide in connection with both physical and psychological abuse and fear of crime Two-fifths of the women and one-fifth of the men reported feeling so unsafe outside their homes that they sometimes refrained from going outside alone. In this study both elderly men and women reporting perceived fear of crime had higher odds ratios of psychological as well as physical symptoms, compared to those not experiencing fear of crime. Perceiving fear of crime was gendered but the associations to ill health were not, except for attempted suicide and suicidal thoughts which had a stronger association in men. Generally perceiving fear of crime was strongly associated to ill health in both women and men.

Based on the literature, it is reasonable to expect that those who have been abused have more health problems, irrespective of age and $\operatorname{sex}^{27-30}$. Very few population-based studies however have assessed the link between elder abuse and health. Some minor studies have been made whose findings in general are similar to what we have found in our study ${ }^{14,31,32}$. In 'The South Carolina Elder Mistreatment Study', researchers demonstrated an association between physical abuse and poor self-rated health, controlling for other predictors. The association between psychological abuse to self-rated health disappeared when controlling for confounders $^{32}$.

In our study, physical abuse was more strongly associated with men's self-reported ill health. This may reflect an actual lower association among women between physical abuse and selfreported health, but could as likely be an artefact caused by the low prevalence of physical 
abuse among women. The demonstrated strong association between psychological abuse and self-rated health in this study resembles the results in one other study ${ }^{31}$. Indeed being psychologically abused might be a more potent negative predictor of poor self-rated health, when comparing to physical abuse. Experienced psychological consequences of abuse could be a sense of powerlessness, shame at having to admit that the abuse is occurring at the hands of close family members, fear of retaliation from the abuser or fear of institutionalisation if the abuse is reported. Such fears might increase the victim's reluctance to report abuse, often causing self-imposed isolation and anxiety ${ }^{16-19}$. Psychological symptoms such as anxiety and depressive symptoms have also been shown to significantly mediate the effect on health status $^{33}$

Significantly more women than men were afraid of crime, and for both men and women fear of crime was more frequent than the experience of actual physical and/or psychological abuse during the past year. Almost half of the women and men who had been exposed to psychological abuse perceived fear of crime, while only a small percentage (especially among the women) had been exposed to physical abuse. Expressed feelings of insecurity due to fear of crime appear to have many underlying causes and to be strongly influenced by beliefs, attitudes and experiences that seldom have to do with actual crime ${ }^{11,21,34,35}$. Yet, perceiving fear of crime in the neighbourhood is associated with increased risk of mobility disability among the elderly, since they refrain from going outside and taking walks ${ }^{22}$. Perceptions of problems in their area (crime, rubbish/litter, traffic, graffiti, for instance) have also been shown to be predictive of poorer health among older people ${ }^{36}$. Although perceiving fear of crime seem to have little connection to victimization, the actual perception and fear of being exposed to a crime strongly relate to ill health both in women and men. This might suggests that the experience of fear of crime could lead to poor health through psychosocial mechanisms like stress and that the mechanisms are shared by both women and men ${ }^{37}$. 
However, in men higher odds ratios are noted specifically for suicidal thoughts and suicidal attempts. Consistent and repeated findings about suicide in elderly confirms that suicide rates are higher in males than females ${ }^{38}$. Overall, research put forward men's' alignment to masculine ideals influencing both the connectedness and detachment between older men's depression and suicide ${ }^{39}$.

The study has some shortcomings, with the main one being its design. Retrospective studies always present several clear shortcomings, but when it comes to the prevalence of abuse and the association between abuse and ill health, they are to date essentially the only method that has been used ${ }^{10,14,36}$. Even so, it is also plausible that ill health e.g. depression and anxiety could lead to a greater perceived experiencing of things as abuse that those who are not unwell may disregard. Another possible limitation is the wording of the questions about abuse, which did not include a specification of various forms of exposure to violence or abuse $^{16-19}$. Moreover the questions about abuse were restricted to incidents during the past year; it would have been beneficial, especially when investigating abuse in relation to health, to be able to control for previous possible abuse. There is a growing body of evidence that adverse early childhood experiences have a profound lifelong impact such as adverse childhood events may predispose people to both victimisation and ill health ${ }^{40}$. On the other hand, limiting the response time window minimises potential recall bias. A third problem was that frequency of abuse was not considered in the response alternatives ${ }^{41}$.

However, the strength of this study compared to earlier studies is the population representative sample, with both sexes reporting and with a more comprehensive list of reported psychological and physical symptoms. The men and women answering the questions about their health did not do so because they had specifically been exposed to abuse, but because they were answering a questionnaire about their general living conditions. In studies 
where specifically abuse-exposed elderly have been interviewed, there may have been a greater bias from the situation.

The most important message emerging from this study is that attentiveness should be paid to abuse in elderly women and men and to the frequent occurrence of fear of crime. Even if abuse in elderly men and women is not very common, it has a great effect on their health. Our study indicates that patterns of abuse and their correlation with ill health among women and men varies, thereby suggesting that different causes, histories and dynamics are at play for different forms of negative health outcomes. The prevalence of abuse varies throughout life but not the negative health outcome, and different forms of abuse affect the health of the victimized, irrespective of age. In a recently published worldwide scan of elderly abuse, encompassing $53 \mathrm{WHO}$ countries, researchers concluded that various services are available to detect abuse and prevent older adults from being abused in principle. However, when identifying the offered services, such as laws, policies, and implementation of knowledge, it was discovered that little effort went into actual detection and prevention ${ }^{42}$. It is a great challenge to all of us working in the social and health sector to be aware of the consequences of elderly abuse and especially to take action against it.

In summary, this study has provided representative results addressing an extensive negative health outcome panorama caused by fear of crime and abuse. These patterns of negative health outcomes were present even when controlling for age, civil status, work history and smoking in both men and women.

\section{Ethical approval}

The Ethics Committee at the Swedish National Board of Health and Welfare approved the survey.

\section{Funding}

None declared. 
Competing interests

None declared. 
Table 1. Sample characteristics stratified according to sex and age, percentage (95\% confidence interval)

\begin{tabular}{|c|c|c|c|c|}
\hline Characteristics & $\begin{array}{r}\text { Women } 65-74 \\
n=2973\end{array}$ & $\begin{array}{r}\text { Men } 65-74 \\
n=2686\end{array}$ & $\begin{array}{r}\text { Women } 75-84 \\
n=2001\end{array}$ & $\begin{array}{r}\text { Men } 75-84 \\
n=1700\end{array}$ \\
\hline \multicolumn{5}{|l|}{ Ethnicity } \\
\hline Born in Nordic country & $87(86-88)$ & $86(85-87)$ & $89(88-90)$ & $91(90-92)$ \\
\hline \multicolumn{5}{|l|}{ Civil status } \\
\hline Married/cohabiting & $74(72-76)$ & $90(89-91)^{\#}$ & $47(45-49)$ & $74(72-76)^{\#}$ \\
\hline Single & $8.1(7.1-9.1)^{\#}$ & $3.9(3.2-4.6)$ & $5.9(4.9-6.9)$ & $5.3(4.2-6.4)$ \\
\hline Widowed & $13(12-14)^{\#}$ & $1.7(1.2-2.2)$ & $41(39-43)^{\#}$ & $11(10-12)$ \\
\hline \multicolumn{5}{|l|}{ Education } \\
\hline Short & $79(78-80)^{\#}$ & $67(65-69)$ & $81^{\#}(79-83)$ & $70(68-72)$ \\
\hline Intermediate & $10(9-11)$ & $25(23-27)^{\#}$ & $11(10-12)$ & $17(15-19)^{\#}$ \\
\hline Long & $11(10-12)^{\#}$ & $8(7-9)$ & $8(7-9)$ & $13(11-15)^{\#}$ \\
\hline \multicolumn{5}{|l|}{ Working history } \\
\hline Manual & $46(44-48)$ & $47(45-49)$ & $54^{\#}(52-56)$ & $45(43-47)$ \\
\hline \multicolumn{5}{|l|}{ Accommodation } \\
\hline Own house/ apartment & $73(71-75)$ & $76(74-78)$ & $63(61-65)$ & $69(67-71)^{\#}$ \\
\hline Rental apartment & $24(22-26)$ & $20(18-22)$ & $32(30-34)^{\#}$ & $25(23-27)$ \\
\hline Other & $3.0(2.4-3.6)$ & $4.0(3.3-4.7)$ & $5.0(4.0-6.0)$ & $6.0(4.9-7.1)$ \\
\hline Insufficient economic margin & $18(17-19)^{\#}$ & $12(11-13)$ & $18(16-20)^{\#}$ & $10(9.0-11)$ \\
\hline Daily smoking & $13(12-14)$ & $12(11-13)$ & $7(6.0-8.0)$ & $11(10-12)^{\#}$ \\
\hline Risk consumption of alcohol & $3.0(2.4-3.6)$ & $7.0(6.0-8.0)^{\#}$ & $0.1(0-0.2)$ & $3.0(2.2-3.8)^{\#}$ \\
\hline
\end{tabular}

\# = Statistically significant different percentage estimate between men and women in the same age category. 
Table 2. Self-reported prevalence of fear of crime and abuse in the population, stratified by sex and age, percentage (95\% confidence interval)

\begin{tabular}{lllll}
\hline Characteristics & Women 65-74 & Men 65-74 & Women 75-84 & Men 75-84 \\
& $\mathrm{n}=2973$ & $\mathrm{n}=2686$ & $\mathrm{n}=2001$ & $\mathrm{n}=1700$ \\
& $\%($ c.i. $)$ & $\%$ (c.i.) & $\%$ (c.i.) & $\%$ (c.i.) \\
\hline Fear of crime & $41(39-43)^{\#}$ & $12(11-13)$ & $44(42-46)^{\#}$ & $18(16-20)$ \\
Psychological abuse & $8.7(7.7-9.7)$ & $8.9(7.8-10)$ & $6.4(5.3-7.5)$ & $5.0(4.0-6.0)$ \\
Physical abuse & $1.0(0.6-1.4)$ & $3.0(2.4-3.6)^{\#}$ & $0.6(0.3-0.9)$ & $0.2(0-0.4)$ \\
\hline
\end{tabular}

\# = Statistically significant different percentage estimate between men and women in the same age category. 


\section{Women}

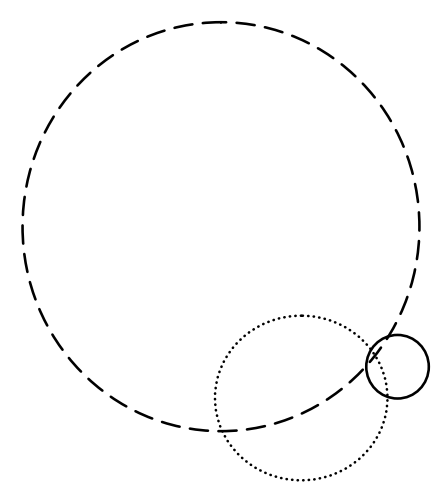

Men

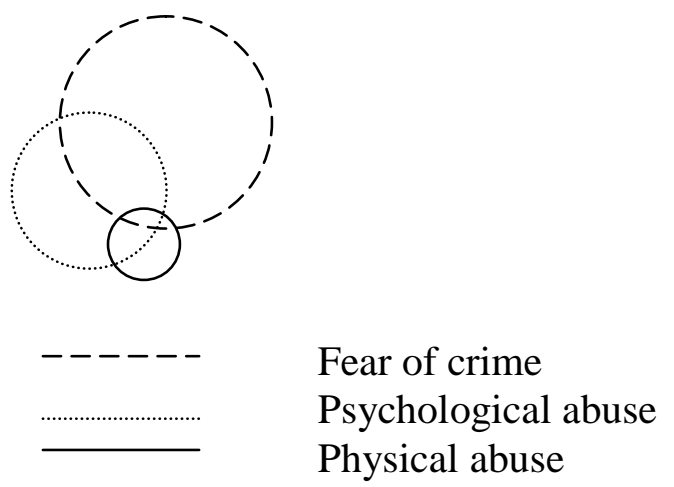

Figure 1. A Venn diagram for women and men aged 65-84 years, demonstrating the overlap of fear of crime, psychological abuse, and physical abuse. 
Table 3. Adjusted odds ratios (OR) and confidence intervals ${ }^{1}$ for health outcomes adjusted for age, civil status, work history and smoking for women and men experiencing fear of crime and/or being psychologically or physically abused during the past 12 months, compared to non-abused (age 65-84).

\begin{tabular}{|c|c|c|c|c|c|c|}
\hline & \multicolumn{2}{|c|}{ Fear of crime } & \multicolumn{2}{|c|}{ Psychological abuse } & \multicolumn{2}{|c|}{ Physical abuse } \\
\hline & Women & Men & Women & Men & Women & Men \\
\hline Poor general & $1.1(1.0-1.1)$ & $1.6(1.1-2.4)$ & $3.8(2.7-5.3)$ & $2.2(1.4-3.4)$ & $1.2(0.5-2.6)$ & $2.2(1.2-4.1)$ \\
\hline \multicolumn{7}{|l|}{ health } \\
\hline Muscular/skeletal & $1.1(0.9-1.3)$ & $1.0(0.8-1.4)$ & $2.2(1.7-2.9)$ & $2.1(1.5-2.9)$ & $2.1(0.7-5.9)$ & $2.6(1.7-4.2)$ \\
\hline \multicolumn{7}{|l|}{ pain (index) } \\
\hline Headache & $1.3(1.1-1.6)$ & $1.7(1.3-2.4)$ & $1.5(1.1-2.0)$ & $2.1(1.4-3.0)$ & $1.5(0.9-2.4)$ & $1.8(1.1-3.2)$ \\
\hline Incontinence & $1.1(0.9-1.3)$ & $1.2(0.8-1.6)$ & $1.6(1.2-2.1)$ & $1.7(1.2-2.4)$ & $1.8(1.2-2.9)$ & $2.3(1.4-3.7)$ \\
\hline Stomach problem & $1.4(1.2-1.6)$ & $1.5(1.1-1.9)$ & $2.0(1.6-2.6)$ & $1.3(1.0-1.9)$ & $1.5(0.9-2.4)$ & $1.1(0.1-1.7)$ \\
\hline Overweight & $1.2(1.1-1.4)$ & $1.5(1.2-2.0)$ & $1.4(1.0-1.8)$ & $1.4(1.0-1.9)$ & $1.3(0.8-2.1)$ & $1.7(1.1-2.7)$ \\
\hline Diabetes & $1.0(0.8-1.2)$ & $1.2(0.9-1.7)$ & $1.4(0.9-2.0)$ & $1.2(0.8-1.9)$ & $1.5(0.8-3.1)$ & $1.7(1.0-2.9)$ \\
\hline Allergy & $1.2(1.0-1.5)$ & $1.8(1.3-2.6)$ & $1.8(1.4-2.5)$ & $2.2(1.5-3.3)$ & $1.8(1.1-3.1)$ & $1.3(0.7-2.4)$ \\
\hline Blood pressure & $1.1(0.9-1.3)$ & $1.3(0.9-1.7)$ & $0.9(0.7-1.2)$ & $1.2(0.9-1.7)$ & $1.2(0.7-2.0)$ & $1.1(0.7-1.7)$ \\
\hline Anxiety & $1.8(1.2-2.9)$ & $1.9(0.9-4.0)$ & $6.3(3.7-11)$ & $10(5.3-19)$ & $7.4(3.6-15)$ & $7.1(3.0-16)$ \\
\hline Sleeping problem & $1.5(1.2-2.0)$ & $2.5(1.6-4.0)$ & $3.0(2.0-4.3)$ & $3.5(2.1-5.9)$ & $2.3(1.4-4.5)$ & $5.1(2.8-9.3)$ \\
\hline Stress & $1.6(1.2-2.3)$ & $3.3(2.0-5.3)$ & $6.3(4.2-9.3)$ & $5.7(3.5-9.5)$ & $3.8(1.9-7.6)$ & $5.9(3.1-11)$ \\
\hline Ghq12 & $1.5(1.2-1.9)$ & $2.2(1.6-3.1)$ & $5.9(4.4-7.9)$ & $3.9(2.7-5.7)$ & $4.0(2.4-6.7)$ & $3.2(1.9-5.5)$ \\
\hline Suicidal thoughts & $1.1(0.8-1.5)$ & $3.7(2.3-5.7)$ & $3.5(2.3-5.2)$ & $7.3(4.6-11)$ & $1.9(0.9-4.3)$ & $4.7(2.4-9.0)$ \\
\hline Attempted suicide & $1.4(0.8-2.4)$ & $4.0(1.8-8.7)$ & $1.1(0.4-2.8)$ & $5.3(2.3-12)$ & $1.4(0.3-6.0)$ & $5.4(1.8-16)$ \\
\hline Pharmaceutical & $1.1(1.0-1.4)$ & $2.0(1.4-2.7)$ & $2.0(1.5-2.7)$ & $2.1(1.4-3.0)$ & $2.1(1.2-3.4)$ & $3.3(2.0-5.4)$ \\
\hline index & & & & & & \\
\hline Use of & $1.3(1.0-1.5)$ & $1.6(1.2-2.1)$ & $2.6(1.9-3.5)$ & $1.4(0.9-2.1)$ & $1.8(1.0-3.1)$ & $1.2(0.7-2.2)$ \\
\hline healthcare inde & & & & & & \\
\hline
\end{tabular}

1. Statistically significant OR are bolded 


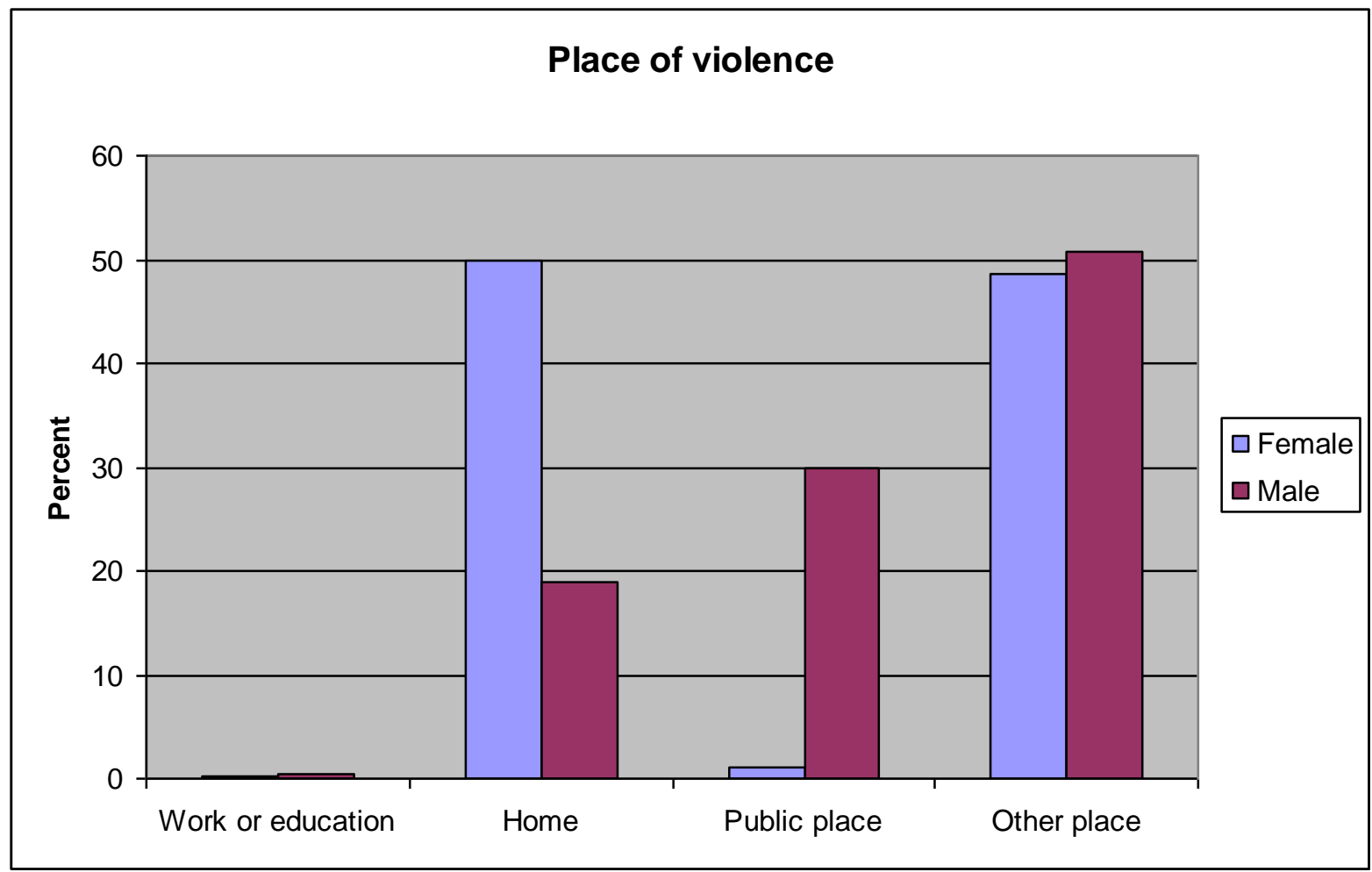

Figure 2. Different places of physical abuse exposure for men and women, given in proportions 


\section{References}

[1] Krug EG, Dahlberg LL, Mercy JA, Zwi AB, Lozano R, eds. World report on violence and health. Geneva: World Health Organization 2002.

[2] Nelson D. Violence against elderly people: a neglected problem. Lancet. 2002 Oct 5;360(9339):1094.

[3] Garre-Olmo J, Planas-Pujol X, Lopez-Pousa S, Juvinya D, Vila A, VilaltaFranch J. Prevalence and risk factors of suspected elder abuse subtypes in people aged 75 and older. J Am Geriatr Soc. 2009 May;57(5):815-22.

[4] Hildreth CJ, Burke AE, Glass RM. JAMA patient page. Elder abuse. Jama. 2009 Aug 5;302(5):588.

[5] Lachs MS, Pillemer K. Elder abuse. Lancet. 2004 Oct 2-8;364(9441):1263-72.

[6] Cooper C, Selwood A, Livingston G. The prevalence of elder abuse and neglect: a systematic review. Age Ageing. 2008 Mar;37(2):151-60.

[7] Phua DH, Ng TW, Seow E. Epidemiology of suspected elderly mistreatment in Singapore. Singapore Med J. 2008 Oct;49(10):765-73.

[8] Watson D, Parsons S. Domestic abuse of women and men in ireland: report on the national study of domestic abuse. Dublin: Stationary Office; 2005.

[9] Bachman R, Dillaway H, Lachs MS. Violence Against the elderly: A Comparative Analysis of Robbery and assault Across Age and Gender Groups. Research on Aging. 1998;20(No. 2, March ):183-98.

[10] Biggs S, Manthorpe J, Tinker A, Doyle M, Erens B. Mistreatment of older people in the United Kingdom: findings from the first National Prevalence Study. J Elder Abuse Negl. 2009 Jan-Mar;21(1):1-14.

[11] McKee K, Milner C. Health, Fear of Crime and Psychosocial Functioning in Older People. Journal of Health Psychology. 2000; Vol 5(4):473-86.

[12] Hayman S. Older people in Canada: their victimization and fear of crime. Can J Aging. 2011 Sep;30(3):423-36.

[13] Fritsch TA, Tarima SS, Caldwell GG, Beaven S. Intimate partner violence against older women in Kentucky. J Ky Med Assoc. 2005 Sep;103(9):461-3.

[14] Fisher BS, Regan SL. The extent and frequency of abuse in the lives of older women and their relationship with health outcomes. Gerontologist. 2006 Apr;46(2):200-9.

[15] Mosqueda L, Burnight K, Liao S. The life cycle of bruises in older adults. J Am Geriatr Soc. 2005 Aug;53(8):1339-43.

[16] Lachs MS, Pillemer K. Abuse and neglect of elderly persons. N Engl J Med. 1995 Feb 16;332(7):437-43.

[17] Dong X, Simon M, Mendes de Leon C, Fulmer T, Beck T, Hebert L, et al. Elder self-neglect and abuse and mortality risk in a community-dwelling population. Jama. 2009 Aug 5;302(5):517-26.

[18] Schonfeld L, Larsen RG, Stiles PG. Behavioral health services utilization among older adults identified within a state abuse hotline database. Gerontologist. 2006 Apr;46(2):193-9.

[19] Mosqueda L, Burnight K, Liao S, Kemp B. Advancing the field of elder mistreatment: a new model for integration of social and medical services. Gerontologist. 2004 Oct;44(5):703-8.

[20] Abbey L. Elder abuse and neglect: when home is not safe. Clin Geriatr Med. $2009 \mathrm{Feb} ; 25(1): 47-60$, vi.

[21] Stafford M, Chandola T, Marmot M. Association between fear of crime and mental health and physical functioning. Am J Public Health. 2007 Nov;97(11):2076-81. 
[22] Clark CR, Kawachi I, Ryan L, Ertel K, Fay ME, Berkman LF. Perceived neighborhood safety and incident mobility disability among elders: the hazards of poverty. BMC Public Health. 2009;9(162):162.

[23] Nilsson P, Orth-Gomér K. Self-rated Health in a european perspective. Stockholm: FRN; 2000.

[24] Burström B, Fredlund N. Self rated health: Is it as good a predictor of subsequent mortality among adults in lower as well as in higher social classes? J Epidemiol Community Health. 2001;55:836-40.

[25] Goldberg DP. The detection of psychiatric illness by questionnaire. A technique for identification and assessment of non-psychotic psychiatric illness. London: Oxford University Press 1972.

[26] Dawson D, Grant B, Stinson F, Zhou Y. Effectiveness of the derived Alcohol Use Disorders Identification Test (AUDIT-C) in screening for alcohol use disorders and risk drinking in the US general population. Alcohol Clin Exp Res 2005;May 29(5):844-54.

[27] Danielsson I, Olofsson N, Gadin KG. [Consequences of violence--a public health issue. Strong connection between violence/threat and illness in both women and men]. Lakartidningen. 2005 Mar 21-Apr 3;102(12-13):938-40, 42.

[28] Olofsson N, Lindqvist K, Gadin K, Danielsson I. Violence against young men and women: a vital health issue. The Open Health Journal. 2009;2:1-6.

[29] Porcerelli JH, Cogan R, West PP, Rose EA, Lambrecht D, Wilson KE, et al. Violent victimization of women and men: physical and psychiatric symptoms. J Am Board Fam Pract. 2003 Jan-Feb;16(1):32-9.

[30] Stickley A, Carlson P. Factors associated with non-lethal violent victimization in Sweden in 2004-2007. Scand J Public Health. 2010 Jun;38(4):404-10.

[31] Ajdukovic M, Ogresta J, Rusac S. Family Violence and Health Among Elderly in Croatia. Journal of Aggression, Maltreatment \& Trauma. 2009;18:261-79.

[32] Cisler JM, Amstadter AB, Begle AM, Hernandez M, Acierno R. Elder mistreatment and physical health among older adults: the South Carolina Elder Mistreatment Study. J Trauma Stress. 2010 Aug;23(4):461-7.

[33] Amstadter AB, Begle AM, Cisler JM, Hernandez MA, Muzzy W, Acierno R. Prevalence and correlates of poor self-rated health in the United States: the national elder mistreatment study. Am J Geriatr Psychiatry. 2010 Jul;18(7):615-23.

[34] Acierno R, Rheingold AA, Resnick HS, Kilpatrick DG. Predictors of fear of crime in older adults. J Anxiety Disord. 2004;18(3):385-96.

[35] Beaulieu M, Leclerc N, Dubé M. Fear of Crime Among the Elderly: An Analysis of Mental Health Issues. Journal of Gerontological Social Work. 2003;40 (4):12138.

[36] Bowling A, Barber J, Morris R, Ebrahim S. Do perceptions of neighbourhood environment influence health? Baseline findings from a British survey of aging. J Epidemiol Community Health. 2006 Jun;60(6):476-83.

[37] Chandola T. The fear of crime and area differences in health. Health Place. 2001 Jun;7(2):105-16.

[38] Shah A. Elderly suicide rates: a replication of cross-national comparisons and association with sex and elderly age-bands using five year suicide data. J Inj Violence Res. $2011 \mathrm{Jul} ; 3(2): 80-4$.

[39] Oliffe JL, Han CS, Ogrodniczuk JS, Phillips JC, Roy P. Suicide from the perspectives of older men who experience depression: a gender analysis. Am J Mens Health. 2011 Sep;5(5):444-54.

[40] Felitti VJ. Adverse childhood experiences and adult health. Acad Pediatr. 2009 May-Jun;9(3):131-2. 
[41] Campbell JC, Lewandowski LA. Mental and physical health effects of intimate partner violence on women and children. Psychiatr Clin North Am. 1997 Jun;20(2):353-74. [42] Podnieks E, Anetzberger GJ, Wilson SJ, Teaster PB, Wangmo T. WorldView Environmental Scan on Elder Abuse. J Elder Abuse Negl. 2010 Jan;22(1-2):164-79.

[43] Douglas AG, David M, Trevor BN, Martin Gj. Statistics with confidence. Second ed. Bristol: BMJ Books 2000. 